\title{
Fra interart studier til intermedialitet
}

\section{Av Jørgen Bruhn}

\section{Interarts studier}

Intermediale studier er et voksende felt inden for moderne humaniora $i$ Europa såvel som i USA, ligesom i resten af verden. Disciplinen, hvis vi i det hele taget kan kalde det for en disciplin, udspringer af en tidligere, ærværdig komparativ tradition, som man kan kalde interart studies (med underafdelinger som word and image studies, word and music studies, etc.). Arts, altså kunstarter, benyttes her synonymt med medier, skal jeg måske lige forudskikke. Og de tre kunstarter/medier, man oftest taler om er ord, billeder, toner - for nu at citere undertitlen på den af Hans Lund redigerede introduktionsbog fra 2002 Intermedialitet. Ord, bild och ton $i$ samspel. Den er hermed anbefalet som en indgang - måske især til interart studier. ${ }^{1}$

Interart studier angår påvirkningsforhold mellem kunstarterne, enten i "blandede" værker, hvor der er flere medier indblandede eller i værker, hvor et værk tydeligt transformerer eller henviser til et andet værk. Arbejdet i denne slags studier kan beskrives ud fra Hans Lunds skema, ifølge hvilket alle tænkelige kunstmøder finder sted som enten kombination (opdelt i interreference eller sameksistens), integration eller transformation ${ }^{2}$ :

\begin{tabular}{llll}
\hline \multicolumn{2}{c}{ Kombination } & Integration & Transformation \\
\hline Interreference & Co-existence & Konkret poesi & Verbal ekfras \\
& & Ljudpoesi & Musikalisk ekfras \\
Illustration & Reklambilder & Typografi & Programmusik \\
Emblematik & Frimärken & Skriftbild & Roman tolkar film \\
Bild \& titel & Lieder/Visor & Bildskrift & Ironisk projicering \\
Musik \& titel & Video & Sprechgesang & Ord tolkar musik \\
Fotojournalistik & Tecknade serier & Konceptkonst & Film tolkar roman \\
Bilderböcker & Opera & Bildalfabet & Teatralisering av text \\
& Liturgi & Ikonicitet & \\
& Affisch & Verbala tecken & \\
& & i bilden & \\
\hline
\end{tabular}

Illustration 1: Hans Lunds skema over intermediale relationer.

Det kan altså dreje sig om filmatiseringer (hvor en roman transformeres til en film). Eller det kan dreje sig om et eksempel på konkret poesi, hvor sproget isprængt et visuelt element udgør digtets uadskillelige og dermed integrerede betydning. Et eksempel:

1 I Norden har bl.a. Hans Lund ydet en stor indsats for kunstkomparationen, men selv om Hans Lund har redigeret det fine samlebind Intermedialitet (Studentlitteratur, Lund 2001) mener jeg ikke, at flertallet af bogens essay eksemplificerer intermedialitet (i min definition af ordet), men snarere interart metoder.

2 Skemaet er fra Hans Lunds Intermedialitet, s. 21. 
Illustration 2: Konkretpoeten Åke Hodells version af Werner von Heidenstam, 1967.

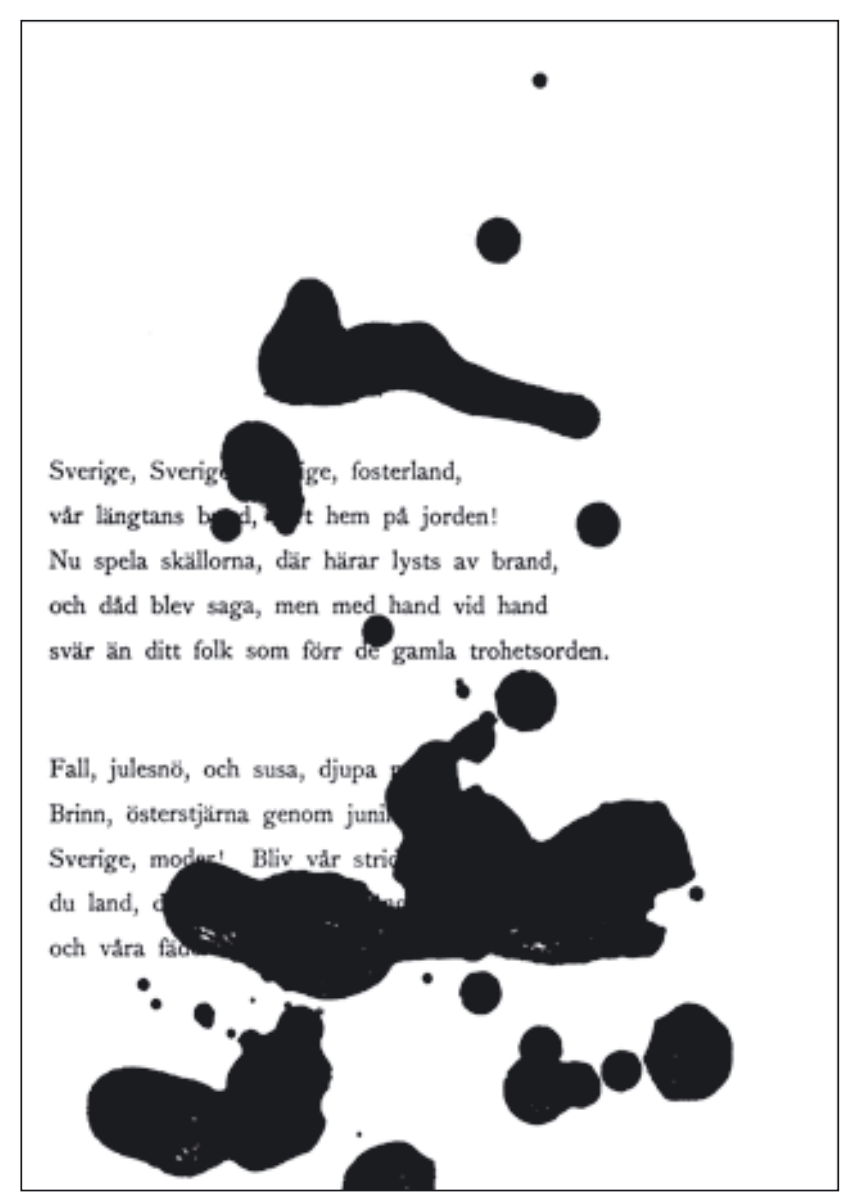

Werner von Heidenstams fædrelandsdigt får et skud for boven her og ser ikke helt så nationalromantisk ud i Åke Hodells version, hvor man hverken kan fjerne blækklatterne (hvis det er blækklatter) - eller det oprindelige digt uden at hele udtrykket afgørende forandres. ${ }^{3}$

En tredje mulighed er en moderne popsang, hvor ord og musik kombineret bliver til sangens enhed: vi kan godt nynne en Beatles-sang uden at kende teksten, og finde fornøjelse i det - og vi kan modsat læse og analysere (men ikke nødvendigvis forstå) "Lucy in the Sky with Diamonds" med et vist udbytte. Men tilsammen giver musik og tekst endnu større mening.

Denne interartbetragtning har affødt en lang række - og afføder stadig - spændende og perspektivrige analyser og fortolkninger. Alligevel synes jeg at denne synsmåde har en tendens til at blive noget repetetiv, og på trods af det næsten uendelige antal eksempel på interart-objekter kan optikken, i hvert fald som forsknings-strategi, blive begrænsende. Man kan godt blive lidt mat i koderne efter et vist antal analyser af forholdet mellem musik og billede i Mussorskijs Peintures d'une Exhibition eller efter at have læst endnu en analyse af modernistiske forfatteres ekfraser (litterære skildringer af kunstværker). Så er det som om disciplinen delvist har nået sin grænse. Kravet om det tværfaglige eller interdisciplinære er afgjort en force, og det udgør en stille protest mod nogle absurde faggrænser, men det på sin vis velfungerende lille felt inden for kulturvidenskaben mangler dynamik og udviklingsmuligheder.

3 Jeg har fundet eksemplet på den spændende hjemmeside http://www.konkretpoesi.se/hodell/vaerker/3.html. 


\section{Intermediale studier}

Anderledes ser det ud med det jeg opfatter som en efterfølger til interartstudierne, nemlig intermediale studier. Mens man, mere eller mindre amateur-mæssigt eller professionelt, har lavet komparative kunststudier i hvert fald siden anden verdenskrig, og endda meget længere tilbage ${ }^{4}$, er det som jeg vælger at kalde intermediale studier en ung videnskabelig disciplin.

Det betyder, at såvel disciplinens objekt som teori og metode er relativt udefinerede. På intermedialitetskonferencer og i centrale udgivelser vil man derfor stadig støde på grundlagsdiskussioner omkring hvad er et medium, hvad er forskellen på multimodalitet og intermedialitet $\mathrm{og}$ så videre - tydelige tegn på at disciplinen er i sin vorden. Set positivt betyder det at man kan kaste sig ind i feltet uden at lade sig tynge af en lang tradition, og at mange muligheder inden for feltet stadig er uudforskede. Negativt betyder det naturligvis at feltet stadig er vaklende defineret, fordi grundpillerrne ikke stikker så dybt i en videnskabelig tradition.

Den bedste definition af feltet er, synes jeg, at man med intermedialitet bevæger sig fra de tværdisciplinære sammenligninger mellem medierne - musik repræsenterer digt, roman bliver til film, ord og billede på plakaten - til en undersøgelse af hvordan et tilsyneladende homogent medium, per definition, inden for mediets egne graenser, har et mellemværende med andre medier.

En vigtig inspirationskilde har for mig været Tom Mitchells arbejde (bl.a. Iconology. Word, Image, Ideology fra 1986 samt Picture Theory fra 1996) som langt fra "kun" er intermediale analyser, men hvis hovedindhold måske alligevel kan koges ned til hans berømte diktum om at "all media are mixed media". Jeg vil formulere det sådan at man med støtte hos bl.a. Mitchell (som især har bevæget sig i feltet mellem visualitet og verbalt sprog) og hos Nicholas Cook (som arbejder ud fra et musikvidenskabeligt synspunkt) kan lade sig inspirere til at tvinge interartanalysen ind $\mathrm{i}$ de enkelte medier for at vise, at alle medieprodukter altid indeholder andre medier. Også selv om de så at sige ikke skilter med det. Set ud fra en intermedial analyse vil ethvert digt altså på en eller anden måde have noget at gøre med enten musikken eller med billedkunsten eller med begge dele. Litteratur, for eksempel, vil altid indeholde musikalske spor i form musikalske strukturer, måske en musikterminologi eller beskrivelser af musikfremførelse - eller i form af prætentioner om at opnå de mål, som normalt tillægges musikken. ${ }^{5}$

Ovenstående er egentlig ikke noget der hos hverken kunstkomparatister eller intermedialister vækker særlige anstød. Men uenighederne opstår, når man skal afgøre hvilken slags relation der findes imellem de medier som mødes (kunstkomparation), eller som findes side om side i det enkelte medie (intermedialitet).

4 Se Claus Clüvers historiske overbliksartikel "Intermediality and Interarts Studies” i Arvidson, Askander, Bruhn, Führer (red.), Changing Borders. Contemporary Positions in Intermediality, Lund Intermedia Press 2007.

5 Jeg har bl.a. diskuteret disse musik-litteratur relationer i forhold til Thomas Manns "Tristan” i ”Tristan Transformed” i ovennævnte Changing Borders. 


\section{Ut pictura poeisis eller Laokoon?}

Tager vi de historiske briller på så har der i æstetikkens historie været forskellige bølger, som har stået på hver sin side i spørgsmålet om hvilket forhold der eksisterer mellem kunstarterne.

Detaljerne i denne lange og komplicerede diskussion vil jeg spare læserne for, men den to tusind år gamle debat kan muligvis resumeres under to overskrifter. "Ut pictura poeisis"tilhængerne på den ene side, som i princippet går ud fra, at de forskellige kunstarter tilhører én familie, og at de forskellige kunstarter så at sige har samme mål, samme indhold, men forskellige udtryksformer. Horats' udtryk ut pictura poeisis, som er revet ud af en større sammenhæng og derfor ofte er blevet misfortolket, kan tages til indtægt for dette: dvs. de samme regler gør sig gældende "i billedkunsten som i poesien". Eller med andre ord: både poesien og billedkunsten kan, når de betragtes under en mimesis-synsvinkel, ses som udtryk for samme bestræbelse. ${ }^{6}$ Dette diktum debatteres i antikken, og i middelalderen lever det videre i de mange og detaljerede diskussioner omkring rimeligheden - eller den praktiske brug af - billeder og skulpturer i kirkeudsmykning. ${ }^{7}$ Og senere, i renæssancen og barokken, fortsættes striden om ideen, men den afvises aldrig. Dog opstår en slags underafdeling til denne tankegang i den såkaldte paragone-debat, der går ud fra kunstarters sammenlignelighed, men som strides om hvilken kunstart som bør indtage førerpladsen i det æstetiske hierarki. Leonardo da Vincis forsvar for malerkunsten er et berømt udtryk for denne strid. En moderne version af denne tanke findes i traditionel narratologi, hvor f.eks. Seymour Chatman i 1980 kan skrive at "[o]ne of the most important observations to come out of narratology is that narrative itself is a deep structure quite independent of its medium." 8

Overfor tanken om kunstarternes kompatibilitet - at ulighederne kun er overfladeforskelle - står en diametralt modsat æstetisk tankegang, som man normalt forbinder med Lessings

6 Det indgår, som Stephen Melville og Bill Readings siger, i "the story about the long Western tradition of comparing the visual and the textual under the auspices of mimesis." Se Stephen Melville og Bill Readings, "General Introduction" i Vision and Textuality, Duke UP, Durham 1995, s. 8.

7 Således kan Honorius fra Autun, ifølge Umberto Eco, tale om maleriets tredobbelte mål, hele tiden betragtet i forhold til troen, som selvfølgelig ligger formuleret på skrift i Bibelen: For det første skal "the house of God [...] be beautified"; for det andet skal det minde om helgernernes liv og færden og endelig er "[p]ainting [...] the literature of the Laity", citeret i Umberto Eco, Art and Beauty in the Middle Ages, Yale UP, 1986, s. 16. Langt senere, i slutningen af det 19. århundrede betragter den britiske kunsthistoriker og forfatter Ruskin på parallel vis de gotiske katedraler (deres form samt udsmykning) som "bøger" for middelalderens analfabeter såvel som for modernitetens gotikdyrkere. Se f.eks. hans Le Bible d'Amiens fra 1880'erne, for ikke at tale om Prousts utallige diskussioner i A la recherche du temps perdu fra begyndelsen af det tyvende århundrede.

8 Og han fortsætter: "In other words, narrative is basically a kind of text organization, and that organization, that schema, needs to be actualized: in written words, as in stories and novels; in spoken words combined with the movements of actors imitating characters against sets which imitate places, as in plays and films; in drawings; in comics strips; in dance movements, as in narrative ballet and in mime; and even in music, at least in program music of the order of Till Eulenspiegel and Peter and the Wolf." Se Seymour Chatman, "What Novels can do that Films Can't (and vice versa)", oprindeligt i Critical Inquiry Vol. 8, 1980, her citeret fra Leo Brady og Marshall Cohen (red.), Film Theory and Criticism (6 $6^{\text {th }}$ ed.) Oxford UP 2004, p. 445. 
opsats om Laokoon. ${ }^{9}$ Denne tekst går for at være en af de første semiotiske afhandlinger, fordi den fokuserer på kunstarterne ud fra deres forskellige tegnsystemer. Titlen på afhandlingen fra 1766 er Laokoon, eller om granserne for malerkunst og digtekunst - og hermed er Lessings hovedidé slået tydeligt fast: der er grænser, der adskiller kunstarterne, som derfor ikke bør sammenblandes, og grænserne skyldes kunstarternes forskellige tegnformer. Det er Lessing, der formulerer en af de - kritisable - naturlove bag megen tænkning omkring kunstarternes forskellighed: at litteratur kun kan og bør udfolde sig over tid, mens maleri og skulptur modsat bør holde sig til rumlige repræsentationer.

Al intermedial teoretiseren må orientere sig mellem kunstkomparationens to væsensforskellige tilgange: enten leder man efter lighederne bag forskellene (ut pictura poesis og alle efterfølgerne) eller også finder man forskellene bag lighederne (Lessings efterfølgere). I denne klassiske grundlagsdiskussion for de intermediale studier forsøger jeg selv at placere mig på Lessings side. Der er, vil jeg mene, grundlæggende forskelle mellem medierne, som bl.a. har at gøre med ordet, tonens og det visuelle tegns forskellige semiotiske karakter. Og det kan være jeg skal understrege, at når jeg taler om semiotik, så tænker jeg ikke på Ferdinand de Saussures semiologi (afgørende for udviklingen af bl.a. strukturel lingvistik og strukturalisme), men snarere på C.S. Peirces semiotik. På den anden side er Lessings position noget forenklet i forhold til kunstarterne. En grundlæggende intermedial pointe går ud på at vi faktisk "læser" billeder, samtidig med at vi ikke kun læser en roman eller et digt, men også "ser" det som et visuelt udtryk.

\section{En drøm om fremtidens intermediale studier}

Tilbage til bestemmelsen af intermediale studier som en efterfølger til kunstkomparationen: Jeg mener at intermedialitetsdiskursen har flere fordele i forhold til interartbetragtningen.

For det første udvides feltet fra at være et mindre, specialiseret område inden for humaniora til i princippet at gælde alle kulturprodukter. På trods af de pædagogiske gevinster ved Hans Lunds skema ovenfor mener jeg at skemaet er begrænsende. Skemaet antyder, at der findes tekster, billeder og musik, som ikke er intermediale - hvilket altså ikke er tilfældet efter min opfattelse. Intermedialitet er ikke videnskaben om lokale særheder i det humanistiske felt, men en disciplin som burde blive den globale grunddisciplin bag alle humanistiske studier.

For det andet kan man ved hjælp af intermedialitetens optik få øje på en indre dynamik i de enkelte kulturprodukter. Dette punkt er afgørende vigtigt - men meget vanskeligt! Hvis intermedialiteten ikke skal blive en formalistisk disciplin, der udelukkende er i stand til at påpege intermediale træk uden at kunne eller ville indsætte disse træk i en større sammenhæng, så mister den en hel del af sin betydning, vil jeg mene. Derfor bør intermediale studier ikke blot fors $\varnothing$ ge at gøre kulturprodukter til modsætningsfyldte enheder - disse modsætninger

9 Søren Kjørup har (i et større handout uddelt ved et seminarium ved Växjö Universitet, foråret 2007) gjort opmærksom på at Lessings ideer i en vis udstrækning stammer fra Lessings ven Moses Mendelsohn. I en indflydelsesrig artikel har Mitchell udformet en ideologisk læsning af Lessings tekst ("The Politics of Genre. Space and Time in Lessing's Laokoon"), som dog imødegås i Bernhard Scholzs indgående diskussion af indholdet af Lessings Laokoon i Changing Borders. 
skal fortolkes som del af et mere omfattende betydningskompleks. Jeg tror at retninger inden for moderne kulturvidenskab kan inspirere arbejdet. Af dekonstruktionen - måske især den franske, filosofiske variant (med Derrida som frontfigur) - kan vi lære at enhver "text" i sig indeholder modsætningsfulde, undergravende elementer, som taler det eksplicitte hovedbudskab midt imod. De hovedmodsætninger som intermediale studier skal forsøge at få fat i , angår ideologiske medbetydninger af genre- og medievalg, det visuelles undertrykkelse af det verbale (og modsat), og lignende problemstillinger. Det vil sige en konfliktorienteret forståelse af det enkelte medies a prioriske heterogenitet. Af ideologikritikken og cultural studies kan vi blive i stand til - som et supplement til den filosofiske eller litterære dekonstruktion - at indsætte det enkelte kulturprodukt i en større ideologisk og kulturel sammenhæng, som ofte vil vise sig at være en helt anden, end producenten af kulturproduktet havde forestillet sig. Og af en af frontfigurerne i den såkaldte postkoloniale retning, Homi Bhabha, kan intermediale studier måske låne træk fra det inspirerende kulturbegreb, der understreger at en kultur (jeg ville oversætte dette med "text") aldrig er homogen og "ren", men per definition er en uren blanding. ${ }^{10} \mathrm{Og}$ i samme åndedrag bør også Bachtins kultur- og litteraturfilosofi nævnes, hvori litterære tekster såvel som kulturudtryk i bredere forstand fortolkes som udtryk for en kamp mellem centrifugale og centripetale kræfter, mellem åbnende og lukkende kræfter, kulturelt, æstetisk og ideologisk. ${ }^{11}$

Måske vil det vise sig at intermediale studier kan blive et felt hvor formalisme og ideologisk forpligtethed kan gå hånd i hånd? Det er ikke umuligt, men det vil kræve en enorm indsats at nå frem til den syntese af omsorgsfuld og nøjagtig mikroanalyse og overordnet historisk og ideologisk overblik, som har haft så svært ved at blive indløst i moderne kulturvidenskab, og hvor pendulet oftest svinger mellem formalisme og ideologisk læsning.

10 Se f.eks. Homi Bhabhas The Location of Culture - eller det spændende interview af Bhabha forestået af WJT Mitchell, på http://prelectur.stanford.edu/lecturers/bhabha/interview.html.

11 Jeg har diskuteret en række af disse aspekter i Romanens tæenker. M.M. Bachtins romanteorier, Multivers 2005. 